\title{
A JORNADA DE TRABALHO DOS BANCÁRIOS E O EXERCÍCIO DO CARGO DE CONFIANÇA
}

\author{
Adriana Delibório ${ }^{1}$, Andréia Delibório ${ }^{2}$ \\ ${ }^{1}$ Toledo Prudente Centro Universitário, Presidente Prudente, SP. ${ }^{2}$ Universidade do Oeste Paulista - UNOESTE, \\ Presidente Prudente, SP. E-mail: adriana.deliborio@hotmail.com
}

\section{RESUMO}

O trabalho científico procurou analisar a jornada de trabalho dos bancários especialmente os ocupantes de cargo de confiança, detentores de fidúcia especial, prevista nas exceções contidas no parágrafo 20 do artigo 224 da CLT e artigo 62, II da CLT. Enfim, a presente pesquisa pretende contribuir para uma melhor definição sobre o que seja cargo de confiança no exercício da função bancária.

Palavras-chave: Bancário, Jornada de Trabalho, Cargo de Confiança, Artigo 224, parágrafo 2ㅇ da CLT e Artigo 62, II da CLT.

\section{THE JOURNEY OF BANK WORKERS AND THE EXERCISES OF CONFIDENCE ROLE}

ABSTRACT: The scientific study sought to analyze the bank working day especially the position of trust of occupants, special fiduciary holders, provided for in the exceptions contained in paragraph 2 of Article 224 of the Labor Code and Article 62, II of the Labor Code. Finally, this research aims to contribute to a better definition of what is position of trust in the performance of the banking function. 


\section{INTRODUÇÃO}

A maioria da demanda trabalhista correlata à categoria dos bancários trata de pedido de jornada de trabalho acima de 6 (seis) horas diárias, cujos demandantes invocam em seu favor a situação prevista no artigo do 224, caput, da CLT. Ocorre que alguns cargos exercidos pelos bancários, assim denominados "cargos de confiança e gestão", a duração da jornada de trabalho se difere, como disposto na exceção do artigo 62, II e o artigo 224, 2 da CLT.

Destarte, os ocupantes de cargo de confiança e gestão recebem tratamento diferenciado quanto à jornada de trabalho de um bancário comum, este último com carga diária é de 06 horas diárias ou 30 horas semanais, posto que os que exercem funções de direção, gerência, fiscalização, chefia e equivalentes, e desde que recebam gratificação função e ou comissão de cargo não inferior a $1 / 3$ (um terço) do salário do cargo efetivo, encontram-se sob a égide do artigo 224 , §2을 da CLT.

Por conseguinte, o enquadramento na exceção prevista no §2o do artigo 224 da CLT, confere ao empregado jornada de 8 horas diárias e 44 horas semanais, fazendo jus ao pagamento da remuneração pelo trabalho que ultrapassar esta jornada, com o acréscimo legal, bem como o amparo de todas as demais normas gerais referentes à duração do trabalho.

Deve-se ressaltar a importância encontrada neste tema, no sentido de não estimular pretensos reclamantes ingressarem no Judiciário pleiteando a condenação de horas extras de forma indevida, o que resta claro o intuito de enriquecimento ilícito daquele demandante.

O presente estudo visa analisar ainda, a jornada de trabalho do bancário, bem como as exceções dispostas na legislação trabalhista e suas especificações, diante de novas decisões do Judiciário sobre o referido tema.

\section{DO EXERCENTE DE CARGO DE CONFIANÇA E DE GESTAO}

A Constituição Federal, em seu artigo 7으, XIII, dispõe que a duração do trabalho normal não pode ser superior a oito horas diárias e quarenta e quatro semanais, sendo que a duração do trabalho do bancário, inferior à jornada normal máxima, trata-se de jornada especial, decorrente de previsão legal.

Os bancários têm jornada de trabalho de seis horas diárias (trinta horas semanais), com direito a quinze minutos de intervalo, em dias úteis, excetuados os sábados. Eis que na legislação trabalhista o sábado é considerado dia útil, não sendo, no entanto, dia de trabalho para o empregado bancário. Assim, o bancário que labutar neste dia haverá de receber horas extras.

Assim, são considerados bancários os empregados em bancos e instituições financeiras. 
Equiparam-se aos bancários, para fins trabalhistas, os que trabalham em empresas de crédito, financiamento ou investimento, como dispõe a Súmula 55 do C.TST.

A jornada de trabalho dos empregados bancários é regida pelos artigos 224, caput, 224, §2 e art. 62, da CLT (Consolidação das Leis Trabalhistas), sendo que as regras especiais sobre a jornada de trabalho do bancário não se aplicam aos ocupantes de cargo de confiança.

Todos os empregados possuem a confiança ordinária de seu empregador, revelada como essencial à manutenção da saudável relação empregatícia. No entanto, alguns possuem fidúcia diferenciada para desenvolver atribuições específicas, com poder de gestão e responsabilidade maior do que a do trabalhador comum. Estes são os considerados exercentes de cargo de confiança.

Por este motivo, os ocupantes de cargo de confiança, ficam afastados da regra geral da jornada de trabalho de 6 horas diárias, por via de exceção, e terá jornada de trabalho de oito horas diárias, com intervalo mínimo para refeição e descanso de uma hora, com direito a perceber gratificação, de no mínimo, um terço do salário do efetivo de seu cargo.

E, a CLT é ínsita ao dispor que:

Art. $224 \S 2$. As disposições deste artigo não se aplicam aos que exercem funções de direção, gerência, fiscalização, chefia e equivalentes, ou que desempenhem outros cargos de confiança, desde que o valor da gratificação não seja inferior a $1 / 3$ (um terço) do salário do cargo efetivo.

Trata-se de tema polêmico na Justiça do Trabalho, uma vez que diante do pedido de horas extras acima da sexta hora diária laborada, pretensos reclamantes pleiteiam o direito as horas extras indevidamente, uma vez que são investidos de cargo de confiança.

Desta forma, são duas as condições para que o bancário que labore além da sexta hora não tenha direito ao pagamento da sétima e oitava hora acrescidas do adicional de jornada extraordinária: que se configure o exercício de uma função de confiança e que a contraprestação econômica não seja inferior a um terço do salário do cargo efetivo, condições estas, cumulativas.

Não basta a simples nomenclatura do cargo para que se configure a função, sendo necessário que reste provado de forma inequívoca um nível diferenciado de fidúcia, uma confiança especial, do banco para com o funcionário.

O que realmente influirá para a solução da lide, será a prova eficaz de que o empregador conferiu ao empregado maior, específica e diferenciada fidúcia e a este.

EVARISTO DE MORAES FILHO assim se pronuncia sobre a figura de que estamos a tratar:

São exercentes de cargos de confiança aqueles que participam dos poderes de gestão ou administração - próprios do titular da empresa. Como que se 
colocam entre o contrato de trabalho e o mandato, obrigando a própria direção de modo direto, através de atos praticados com representação. Os seus exercentes não possuem outro título legítimo para a sua ocupação além da livre e espontânea escolha do empregador. Realizam atos que deveriam ser praticados pessoalmente pelos titulares do negócio, daí a confiança imediata de que se revestem. Podem ser cargos de direção, de gestão, de gerência, como igualmente de guarda de valores vultosos da empresa". ("Tratado Elementar de Direito do Trabalho", 1960, vol. I, págs. 434/435).

Assim, poderíamos conceituar "cargo de confiança" como sendo aquele que é exercido pelo empregado, a quem o empregador confere uma especial confiança (artigo 224, §20 da CLT) ou uma maior carga de responsabilidade e de representação (artigo 62, II da CLT), importando para o obreiro no exercício de atividade própria daquele, por delegação ou mandato, e cujo exercício poderá influir decisivamente na vida e no desenvolvimento da empresa.

Para a configuração do cargo de confiança, embora o empregado tenha fidúcia diferenciada, não se deve exigir, entretanto, que esteja investido em amplos e gerais poderes de gestão, ao passo de decidir sobre interesses fundamentais do empregador, sendo bastante que possua uma posição relevante e de destaque na unidade em que atua.

Tal posição se revela no desempenho de tarefas de fiscalização, coordenação e direção sobre o trabalho de outros empregados, poder de decisões, participação de comitê de crédito, com a responsabilidade efetiva na administração da agência bancária, revelando a fidúcia especial depositada no empregado.

Poder de confiança esse que embora não investido em amplos e gerais poderes de gestão, ao passo de decidir sobre interesses fundamentais do empregador, bastante que possua uma posição de destaque e relevância na unidade em que atua.

O digno Desembargador Federal do Trabalho Sérgio Pinto Martins assim enfrenta a matéria:

\begin{abstract}
Para caracterizar o cargo de confiança não se exige amplos poderes de mando, representação e substituição do empregador. Entretanto, o empregado bancário deve exercer alguma função de chefia ou semelhante, ou desempenhar efetivamente algum cargo de confiança. Para ser chefe, é preciso ter chefiados, poder advertir seus subordinados, ter assinatura autorizada. (...) A simples nomenclatura dada ao cargo não irá caracterizá-lo como de confiança, além do que a prova do cargo de confiança pertence à empresa por se tratar de fato impeditivo do direito à $7 \underline{a}$ e $8^{\underline{a}}$ horas como extras.
\end{abstract}

Atente-se, ainda, que a falta de subordinados não descaracteriza o exercício do cargo previsto no art. $224, \S 2 \circ, \mathrm{CLT}$. 
Saliente-se que os referidos empregados são excluídos da jornada especial de seis horas, não fazendo jus a sétima e oitava hora como extras, porém, conforme o Tribunal Superior do Trabalho (TST), às horas suplementares, excedentes da oitava, farão jus, exceto quando investidos de mandato, em forma legal, tenham encargos de gestão e usufruam padrão salarial que os diferenciem dos demais empregados.

Sendo assim, não resta dúvida de que as funções elencadas neste tópico por tratar de situação diferenciada dos demais, ou seja, de um caixa bancário, por ter sobre si depositada elevada confiança por parte do empregador, o enquadramento a-se perfeitamente no $\S 20$ do artigo 224 da CLT.

Em suma, o artigo 224, §2ㅇ da CLT trata-se in casu a cargos como os chefes de departamento e/ou filial, diretores ou equivalentes. Portanto tais cargos guardam consonância com a Súmula $\mathbf{2 8 7}$ do C.TST, 1a parte que descreve que: "a jornada de trabalho do empregado de banco gerente de agência é regida pelo art. 244, \& 2ㅇ, CLT."

Os bancários que cumprem jornada de oito horas, mesmo que remunerados com gratificação, cujo cargo não configure função de confiança, terão por direito haver da instituição financeira as horas excedentes à sexta, adicionadas do percentual de cinqüenta por cento.

Já o artigo 62, inciso II da CLT prevê a figura do empregado exercente de cargo de gestão. Trata-se de bancário que por conta da posição ocupada, detém amplos poderes de mando e, percebe remuneração diferenciada.

Importante frisar que todo exercente de cargo de gestão é também exercente de cargo de confiança, mas que nem todo aquele que exerce o cargo de confiança tem poder de gestão, mas uma fidúcia diferenciada dos outros empregados normais.

Dispõe o artigo 62,II da CLT:

CLT, Art. 62 - Não são abrangidos pelo regime previsto neste capítulo: (Redação dada pela Lei no 8.966, de 27.12.1994) II - os gerentes, assim considerados os exercentes de cargos de gestão, aos quais se equiparam, para efeito do disposto neste artigo, os diretores e chefes de departamento ou filial. (Incluído pela Lei no 8.966, de 27.12.1994).

Também chamado de gestor, tal empregado representa a figura do próprio empregador. Conta com maior poder de mando, gestão, coordenação, ascendência hierárquica, fiscaliza, supervisiona e aplica penalidades. Para os que exercem essas funções de gestão, não há limitação da jornada de trabalho. Não há sequer controle desta, eis que é da essência do cargo a ampla liberdade e autonomia.

Referido empregado bancário não terá direito a horas extras, por expressa determinação 
legal. A remuneração diferenciada que percebe, já faz supor que o referido empregado gestor esteja suficientemente pago por eventual labor excedente que venha dispensar em prol do empregador.

Por conta disso, o gerente geral de agência, goza de maior destaque e benefícios, sempre tendo o status de representante local do empregador, exerce assim cargo de gestão e confiança.

Aplicável ao gerente geral a Súmula 287 do C. TST:

A jornada de trabalho do empregado de banco gerente de agência é regida pelo art. 224, § 2ㅇ, CLT. Quanto ao gerente-geral de agência bancária, presume-se o exercício de gestão, aplicando-se o art. 62 da CLT.

Além de ser a autoridade máxima da agência bancária e diante dos poderes de confiança a ele depositado pelo Banco, o gerente geral recebe gratificação pela função superior a 40\%.

Diferentemente dos bancários apenas exercentes de cargo de confiança bancária com jornada de trabalho inserida na disposição do artigo $224, \S 2 \stackrel{\circ}{ }$, da CLT, o gerente geral, exercente de cargo de gestão tem excluída as horas extras, nos termos do artigo 62, II, da CLT.

\section{CONCLUSÃO}

Do exposto, infere-se que este trabalho teve por intuito analisar, sem, contudo esgotar, todas as questões que dizem respeito aos exercentes de cargo de confiança e sua jornada de trabalho.

O presente estudo abordou também a distinção dos artigos 224,§ 2 ㅇ da CLT e o artigo 62, II, da CLT face a função de confiança.

Certo é que a função de confiança prevista no art. 224,§2으, da CLT é diversa da prevista no art. 62, II, do mesmo diploma legal. A função de que trata o art. 224,§2º, da CLT não exige amplos poderes de mando, ou seja, não pressupõe representatividade da empresa pelo empregado, mas apenas maior responsabilidade, tendo como jornada de trabalho 08 (oito) horas diárias e 44 (quarenta e quatro semanais), ao passo que o exercente de cargo de gestão, é dispensado controle de jornada de trabalho.

Foi possível também verificar a importância do tema relacionado a jornada de trabalho dos bancários exercentes de cargo de confiança e gestão, uma vez que suas reclamações trabalhistas propostas na Justiça do Trabalho em regra relacionam-se a pedido de horas extras, muitas vezes indevido, em uma tentativa de enriquecimento ilícito.

Equivocadamente, demandas são propostas por bancários que postulam horas extras além da 6ạ diária, tendo estes recebidos a gratificação decorrente do cargo/função e posteriormente 
mitigam os referidos poderes atribuídos no contrato de trabalho.

De suma importância também são as decisões e a evolução dos Julgadores nas decisões quanto à condenação de horas extras, os quais em análise ao conjunto probatório da existência de cargo de confiança, excluem a condenação de horas extras além da 6ạ diária e, diante do cargo de gestão excluem por total o pagamento de qualquer jornada extraordinária.

Portanto, diante das questões apresentadas, o que não pretende é que o Judiciário inflame de ações indevidas, face aos pedidos de horas extras, que conforme demonstrado, deverão ser julgados improcedente, evitando assim o enriquecimento ilícito de certos demandantes.

\section{REFERÊNCIAS}

CATHARINO, JOSÉ MARTINS. Contrato de Emprego. 2ae ed. Rio de Janeiro: 1965.

MARANHÃO, DÉLIO MARANHÃO. Instituições de Direito do Trabalho. 16ạ ed. São Paulo: LTr, 1996.

MARTINS, SÉRGIO PINTO. Direito do Trabalho. 6ạ ed. São Paulo, 1998.

FILHO, EVARISTO DE MORAES. Tratado Elementar de Direito do Trabalho. Volume I: 1960.

ROMAR, Carla Teresa Martins Romar. Coordenador: Pedro Lenza. Direito do Trabalho Esquematizado. São Paulo: Saraiva, 2013.

ROMAR, Carla Teresa Martins. Direito do Trabalho e Direito Processual do Trabalho. São Paulo: Atlas, 2010. ISBN: 978-85-224-5839-4.

SAAD, Eduardo Gabriel. Curso de direito do Trabalho. São Paulo: LTr, 2000. ISBN: 85-7322-855-5 SARAIVA, Renato. Direito do Trabalho. 2a ed. revista e atualizada. Versão universitária. São Paulo: Método, 2009.

VENEZIANO, André Horta Moreno Veneziano. Direito e Processo do Trabalho. 3a ed. revista e atualizada. São Paulo: Saraiva, 2010. 